\title{
Global Distribution of Human Protoparvoviruses
}

\author{
Elina Väisänen, Ushanandini Mohanraj, Paula M. Kinnunen, ${ }^{1}$ Pikka Jokelainen, Haider Al-Hello, \\ Ali M. Barakat, Mohammadreza Sadeghi, ${ }^{2}$ Farid A. Jalilian, Amir Majlesi, Moses Masika, \\ Dufton Mwaengo, Omu Anzala, Eric Delwart, Olli Vapalahti, Klaus Hedman, Maria Söderlund-Venermo
}

Development of next-generation sequencing and metagenomics has revolutionized detection of novel viruses. Among these viruses are 3 human protoparvoviruses: bufavirus, tusavirus, and cutavirus. These viruses have been detected in feces of children with diarrhea. In addition, cutavirus has been detected in skin biopsy specimens of cutaneous T-cell lymphoma patients in France and in 1 melanoma patient in Denmark. We studied seroprevalences of $\lg G$ against bufavirus, tusavirus, and cutavirus in various populations ( $n=840$ ), and found a striking geographic difference in prevalence of bufavirus IgG. Although prevalence was low in adult populations in Finland (1.9\%) and the United States (3.6\%), bufavirus IgG was highly prevalent in populations in Iraq (84.8\%), Iran (56.1\%), and Kenya (72.3\%). Conversely, cutavirus IgG showed evenly low prevalences (0\%-5.6\%) in all cohorts, and tusavirus IgG was not detected. These results provide new insights on the global distribution and endemic areas of protoparvoviruses.

Darvoviruses are small, nonenveloped, single-stranded 1 DNA viruses that infect a wide variety of animals ranging from insects and shrimp to birds and mammals. Human parvoviruses belong to 4 genera: Erythroparvovirus, Bocaparvovirus, Tetraparvovirus, and Dependoparvovirus (1). The recently described bufavirus, tusavirus, and cutavirus are the first members of the genus Protoparvovirus found in humans. All 3 viruses were identified

Author affiliations: University of Helsinki, Helsinki, Finland (E. Väisänen, U. Mohanraj, P.M. Kinnunen, P. Jokelainen, O. Vapalahti, K. Hedman, M. Söderlund-Venermo); Statens Serum Institut, Copenhagen, Denmark (P. Jokelainen); Estonian University of Life Sciences, Tartu, Estonia (P. Jokelainen); National Institute for Health and Welfare, Helsinki (H. Al-Hello); Al-Hussein Teaching Hospital, Thi-Qar Governorate, Iraq (A.M. Barakat); Blood Systems Research Institute, San Francisco, California, USA (M. Sadeghi, E. Delwart); University of California, San Francisco (M. Sadeghi, E. Delwart); Hamadan University of Medical Sciences, Hamadan, Iran (F.A. Jalilian, A. Majlesi); University of Nairobi, Nairobi, Kenya (M. Masika, D. Mwaengo, O. Anzala); Helsinki University Hospital, Helsinki (O. Vapalahti, K. Hedman)

DOI: https://doi.org/10.3201/eid2407.172128 by next-generation sequencing and metagenomics in feces of children with diarrhea: bufavirus from Burkina Faso in 2012, tusavirus from Tunisia in 2014, and cutavirus from Brazil and Botswana in 2016 (2-4). In addition, cutavirus was detected by in silico analysis of existing next-generation sequencing libraries and by PCR of malignant skin tissues of patients in France with cutaneous T-cell lymphoma (4).

To date, 3 genotypes of bufavirus have been detected, and bufavirus DNA has been detected in 1 nasal swab specimen of a child in Finland and in $\leq 4 \%$ of fecal samples from patients with diarrhea in Africa, Europe, and Asia (2,5-13). Recently, a bufavirus 3 sequence was reported in a fecal sample in Peru, which expanded the geographic locations where bufavirus has been detected (14). All of these studies have reported DNA sequences of either bufavirus 1 or 3 ; bufavirus 2 DNA has been detected only in 1 child in Burkina Faso. Humans have been shown to have $\operatorname{IgG}$ against all 3 bufavirus genotypes, which also seem to represent distinct serotypes (12).

Although the seroprevalence of bufavirus in Finland was found to be low $(3.1 \%$ in children and in adults born in Finland), the presence of bufavirus IgG in 5/12 adults originating from Asia suggested that the bufavirus prevalence might be higher in other continents. Furthermore, the strong IgG responses indicate that these 3 viruses might cause systemic infections similar to other known human parvoviruses, such as human parvovirus B19, human bocaviruses, and human parvovirus 4 (15). In addition to bufavirus in humans, several animal species, including nonhuman primates, shrews, bats, rats, swine, and fur seals, have been shown to be infected with specific bufavirus-like viruses (16-23).

Conversely, tusavirus DNA has been detected only in feces of 1 child in Tunisia (3). In addition, 1 of 228 children in Finland showed a low-level IgG response (12). However, these findings are scarce, and more studies are needed to determine whether tusavirus is truly a human virus.

${ }^{1}$ Current affiliation: Finnish Food Safety Authority Evira, Helsinki, Finland.

${ }^{2}$ Current affiliation: University of Turku, Turku, Finland. 
Cutavirus is the newest member of the human parvoviruses. This virus was originally detected in feces of children with diarrhea in 2016; cutavirus DNA was also detected in cancerous tissues of 4/17 patients in France with cutaneous T-cell lymphoma (4). Although test results for other skin cancer types and healthy skin examined in this study were negative for cutavirus, 1 melanoma patient in Denmark was shown to have cutavirus DNA in malignant skin (24).

The etiologic roles of bufavirus, tusavirus, and cutavirus in human disease remain uncertain and more studies are needed. In this study, we developed a new cutavirus IgG enzyme immunoassay (EIA) and combined it with our existing IgG EIA panel of bufavirus genotypes 1-3 and tusavirus. We then analyzed 6 human populations on 4 continents for IgG against these 3 protoparvoviruses. We included veterinarians from Finland $(n=324)$ to assess the possible contribution of human-animal contact; adults from the United States $(\mathrm{n}=84)$, Iraq $(\mathrm{n}=99)$, and Iran ( $=107)$; and adults $(\mathrm{n}=119)$ and children $(\mathrm{n}=107)$ from Kenya to identify age-related and geographic distributions of these emerging viruses in humans.

\section{Materials and Methods}

\section{Study Cohorts}

The cohorts included in the study were from 5 countries on 4 continents. The study and all sampling were conducted in accordance with relevant guidelines and regulations.

For the veterinary cohort from Finland, we obtained serum samples from 324 healthy adult volunteers (Table 1). Samples were collected from participants at the national Annual Veterinary Congress in 2009 in Helsinki, Finland
(25). Most $(82 \%)$ of the volunteers were veterinarians, veterinary students, or veterinary nurses, and $92 \%$ completed an electronic questionnaire to obtain background information. Written informed consent was obtained from all study participants, and the study was approved by the Ethics Committee of Helsinki University Central Hospital.

For the cohort from the United States, we obtained serum samples from 84 healthy blood donors at Blood Systems Research Institute (San Francisco, CA, USA) (Table 1). The samples were collected during April 2009 in 2 locations (Arizona $[n=40]$ and Mississippi $[n=44]$ ). Under US human and health service regulations, the study of preexisting, deidentified samples is not classified as human subject research.

For the cohort from Iraq, we obtained serum samples from 99 healthy adults (Table 1) to assess exposure of the population to various virus infections in Nasiriyah, Dhi Qar, in southern Iraq (26). Written informed consent was obtained from all study participants, and the study was approved by the Ethics Committees of Medical Sciences at Basrah University and the Al-Hussein Teaching Hospital.

For the cohort from Iran, we obtained serum samples from 107 healthy adults (Table 1) at the Hamadan Blood Transfusion Organization (Hamadan, Iran). Informed consent was waived for analysis of these deidentified blood donor samples, and the study was approved by the Ethics Committee of Hamadan University of Medical Sciences.

For the cohort from Kenya, we obtained serum samples from 107 children and 119 adults who had a febrile illness of unknown cause and had visited health clinics in Mwatate, Voi, or Wundanyi in Taita Taveta County in southern Kenya (Table 1). A questionnaire

\begin{tabular}{|c|c|c|c|c|c|c|}
\hline Cohort & $\begin{array}{c}\text { No. } \\
\text { persons }\end{array}$ & Health status & $\begin{array}{l}\text { Mean age, y } \\
\text { (range) }\end{array}$ & $\begin{array}{c}\text { No. (\%) } \\
\text { male:female; } \\
\text { unknown }\end{array}$ & $\begin{array}{c}\text { Time of sample } \\
\text { collection }\end{array}$ & Other features \\
\hline Finland & 324 & Constitutionally healthy & $40.2(19-79)$ & 45 (13.9):279 (86.1) & 2009 Oct & $\begin{array}{c}\text { Adults: } \\
\text { veterinarians }\end{array}$ \\
\hline United States & 84 & Constitutionally healthy & $41.3(18-72)$ & 64 (76.2):20 (23.8) & 2009 Apr & $\begin{array}{l}\text { Adults: blood } \\
\text { donors }\end{array}$ \\
\hline Iraq & 99 & Constitutionally healthy & 39.7 (18-60) & 71 (71.4):28 (28.3) & 2013 Nov-Dec & $\begin{array}{l}\text { Adults: medical } \\
\text { staff, blood } \\
\text { donors, and } \\
\text { university students }\end{array}$ \\
\hline Iran & 107 & Constitutionally healthy & $42.2(18-77)$ & 50 (46.7):57 (53.3) & 2015-2016 & $\begin{array}{l}\text { Adults: blood } \\
\text { donors }\end{array}$ \\
\hline Kenya, children & 107 & $\begin{array}{c}\text { Febrile at time of } \\
\text { sampling (mean } \\
\text { temperature } 38.6^{\circ} \mathrm{C} \text {, } \\
\text { range } 37.5^{\circ} \mathrm{C}-40.4^{\circ} \mathrm{C} \text { ) }\end{array}$ & $6.9(0.5-17.8)$ & $\begin{array}{c}59(55.1): 43(40.2) \\
5(4.7) \dagger\end{array}$ & 2016 Apr-Aug & $\begin{array}{c}\text { Children: includes } \\
9 \mathrm{HIV}+(8 \\
\text { receiving HAART })\end{array}$ \\
\hline Kenya, adults & 119 & $\begin{array}{l}\text { Febrile at time of } \\
\text { sampling (mean } \\
\text { temperature } 38.9^{\circ} \mathrm{C}, \\
\left.\text { range } 37.5^{\circ} \mathrm{C}-39.8^{\circ} \mathrm{C}\right)\end{array}$ & $43.3(18.2-88.3)$ & $\begin{array}{c}42(35.3): 76(63.9) \\
1(0.8) \dagger\end{array}$ & 2016 Apr-Nov & $\begin{array}{l}\text { Adults: includes } \\
38 \text { HIV+ (35 } \\
\text { receiving HAART) }\end{array}$ \\
\hline
\end{tabular}


to obtain background information and symptoms was completed by all patients, and written informed consent was obtained from all study participants or guardians of children. The study was approved by the Kenyatta National Hospital-University of Nairobi Ethics and Research Committee.

\section{Serologic Analysis}

\section{Cutavirus Capsid Protein 2 Virus-Like Particles}

To analyze serum samples for IgG against all human protoparvoviruses, we included cutavirus in an in-house EIA panel for bufavirus genotypes $1-3$ and tusavirus (12). The virus capsid protein 2 (VP2) gene for cutavirus was cloned from the original DNA extract from feces of the cutavirus DNA-positive child from Brazil (Br337) (4) by using primers VP2 fwd Br337 BamHI (5'-TAggatccATGTCAGAACCAGCTAATGATAC-3') and VP2 rev Br337 SalI (5'-CTCgtcgacTTACAATGTGTAGTTTGGTAGACA-3') (restriction sites are indicated by lowercase letters).

The obtained VP2 (GenBank accession no. MH127919) was used to create a recombinant baculovirus with the Bac-to-Bac system (Invitrogen, Carlsbad, CA, USA), according to the manufacturer's instructions, and cutavirus VP2 virus-like particles (VLPs) were expressed and purified as described for bufavirus VP2 VLPs and tusavirus VP2 VLPs (12).

\section{Combined Bufavirus 1-3/Tusavirus-Cutavirus IgG EIA}

We analyzed all serum samples by using the combined bufavirus 1-3/tusavirus-cutavirus IgG EIAs, with insect cell lysate as a control antigen, as described, but included cutavirus VLP antigen in separate wells (12). In brief, we applied biotinylated antigens (VP2 VLPs, $80 \mathrm{ng} /$ well) or cell lysate control to streptavidin-coated plates. After incubation and postcoating, we applied serum diluted 1:200 to each well. To detect bound $\mathrm{IgG}$, we used horseradish peroxidase-conjugated antihuman $\operatorname{IgG}$ as the secondary antibody and 3,3',5,5'-tetramethylbenzidine (Dako, Santa Clara, CA, USA) as the substrate.

We measured optical densities (ODs) at $450 \mathrm{~nm}$ (Multiskan EX; Thermo Fischer Scientific, Pittsburgh, PA, USA) and subtracted blank ODs from test ODs to get the final OD. We confirmed all samples with an $\mathrm{OD} \geq 0.1$ by using a competition assay, as described $(12,27)$. In the competition assay, serum antibodies were blocked separately with 3 unbiotinylated antigens in solution: the same (homologous) antigen as in the EIA, the heterologous antigen of the phylogenetically closest protoparvovirus, and the heterologous antigen of a more distant protoparvovirus, before repeating the EIAs. A sample was considered IgG positive when full homologous blocking but no (or partial) heterologous blocking occurred, as described (12).

\section{Statistical Analysis}

We performed statistical analysis by using $2 \times 2$ tables and test statistics (mid p-exact value) in OpenEpi software

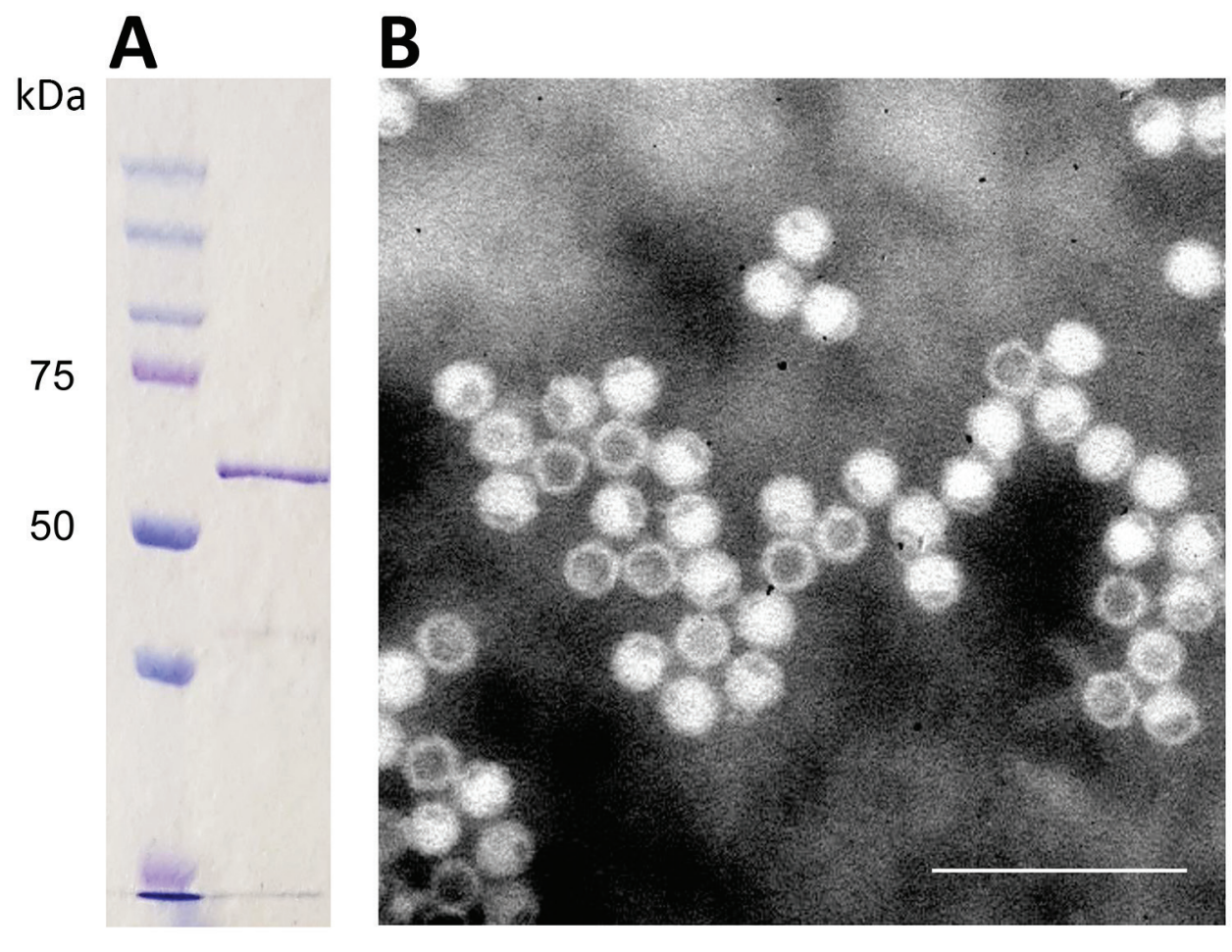

Figure 1. Identification of cutavirus from human serum samples. A) Sodium dodecyl sulfate-polyacrylamide gel electrophoresis of virus capsid protein 2. Lane M, protein size marker; lane C, cutavirus. B) Electron micrograph of cutavirus virus-like particles. Scale bar indicates $100 \mathrm{~nm}$. 
(https://www.OpenEpi.com). A 2-tailed p value $<0.05$ was considered statistically significant.

\section{Results}

\section{Cutavirus IgG EIA and Cross-Reactivity of IgG}

Sodium dodecyl sulfate-polyacrylamide gel electrophoresis identified cutavirus VP2s of expected size $(\approx 64 \mathrm{kDa})$ (Figure 1, panel A). Electron microscopy identified parvovirus-like VLPs with a diameter of $\approx 25 \mathrm{~nm}$ (Figure 1, panel B).

In the cutavirus IgG EIA, it was evident that bufavirus 2 and cutavirus cross-react: in all samples with an OD $>0.5$ for bufavirus 2 or cutavirus, a reaction was always observed with the other antigen. In samples showing weak reactivity (OD 0.1-0.5) in cutavirus or bufavirus 2 IgG EIAs, both cross-reactivities and single-specific reactivities were observed. In the competition assay, the specific reactivity of bufavirus or cutavirus was blocked completely only by homologous antigen, whereas cross-reactive reactions were blocked by homologous and heterologous antigens. In several instances, heterologous antigen slightly reduced the specific EIA reactivity; however, this reduction was much less than that caused by homologous antigen.

In cohorts from the Middle East and Africa that showed high prevalences of bufavirus IgG, some crossreactivity was also observed among the 3 bufavirus genotypes, mostly for samples with higher ODs. However, the competition assay used for all positive samples could distinguish genotype-specific reactivity for correct interpretation. Tusavirus IgG did not cross-react with bufavirus IgGs or cutavirus IgG.

\section{Bufavirus IgG in Adults}

Bufavirus IgG was rare among veterinarians from Finland and blood donors from the United States: only $1.9 \%$ of the veterinarians and $3.6 \%$ of the blood donors had bufavirus IgG (Table 2). In these cohorts, each bufavirus IgG-positive person had antibodies against only 1 bufavirus genotype. No indications of specific animal contact being associated with bufavirus seropositivity were found when we compared background information for bufavirus
IgG-positive and bufavirus IgG-negative veterinarians. For blood donors from the United States, all 3 bufavirus IgG-positive samples were from Mississippi. However, all samples from Arizona were negative for bufavirus IgG. The most commonly detected genotype was bufavirus 1 in Finland and bufavirus 3 in the United States (Table 2).

In striking contrast to adults from the United States and Finland, including our previous results for students and staff members from Finland (12), bufavirus IgG was common in Iraq, Iran, and Kenya, for which $84.8 \%, 56.1 \%$, and $72.3 \%$, respectively, of adult populations had $\operatorname{IgG}$ against $\geq 1$ bufavirus genotypes (Table 2 ). In the Middle East, bufavirus 1 was the most common type, whereas in Kenya, bufavirus 3 was the predominant genotype (Table 2). Bufavirus 2 was the second most prevalent bufavirus in all 3 high-prevalence countries. In Iraq, we found that $30(30.3 \%)$ of 99 persons had antibodies against 2 bufavirus genotypes, and 7 (7.0\%) of 99 persons had antibodies against all 3 bufavirus genotypes. In adults from Kenya, we found similar prevalences: $30(25.2 \%)$ of 119 persons had antibodies against 2 bufavirus genotypes, and $6(5.0 \%)$ of 119 persons had antibodies against all 3 bufavirus genotypes. However, in Iran, we found that double or triple prevalences were lower: $14(13.1 \%)$ of 107 persons had antibodies against 2 bufavirus genotypes, and 2 $(1.9 \%)$ of 107 persons had antibodies against all 3 bufavirus genotypes.

In Kenya, HIV-positive patients had a similar bufavirus IgG prevalence as the rest of the cohort: $78.9 \%(30 / 38)$ in HIV-positive adults (mean age 46.3 years, range $27-85$ years) vs. $69.1 \%(56 / 81)$ in HIV-negative adults (mean age 41.9 years, range $18-88$ years $)(p=0.275)$. When we compared only the $38 \mathrm{HIV}$-positive persons and $60 \mathrm{HIV}$ negative persons within the same age range (27-85 years), bufavirus seroprevalences were even more similar: $79 \%$ for $\mathrm{HIV}$-positive persons and 75\% for HIV-negative persons $(p=0.669)$. However, possible undiagnosed cases of infection with HIV and unequal numbers could affect the accuracy of this comparison.

When the adult cohorts were analyzed more closely and persons were divided by age into equal-sized groups

\begin{tabular}{|c|c|c|c|c|c|c|c|}
\hline \multirow[b]{2}{*}{ Cohort } & \multirow{2}{*}{$\begin{array}{c}\text { No. } \\
\text { persons }\end{array}$} & \multirow{2}{*}{$\begin{array}{c}\text { Any bufavirus } \\
\text { lgG† }\end{array}$} & \multicolumn{3}{|c|}{ IgG against bufavirus genotypes } & \multirow{2}{*}{$\begin{array}{c}\text { Tusavirus } \\
\text { IgG }\end{array}$} & \multirow{2}{*}{$\begin{array}{c}\text { Cutavirus } \\
\lg G \ddagger\end{array}$} \\
\hline & & & 1 & $2 \ddagger$ & 3 & & \\
\hline Finland, healthy adults (veterinarians) & 324 & $6(1.9)$ & $4(1.2)$ & $1(0.3) \S$ & $1(0.3)$ & 0 & $16(4.9) \S$ \\
\hline United States, healthy adults & 84 & $3(3.6)$ & 0 & 0 & $3(3.6)$ & 0 & 0 \\
\hline Iraq, healthy adults & 99 & $84(84.8)$ & $80(80.8)$ & 33 (33.3) & $15(15.2)$ & 0 & $1(1.0) \mathbb{1}$ \\
\hline Iran, healthy adults & 107 & $60(56.1)$ & $55(51.4)$ & $17(17.9)$ & $6(5.6)$ & 0 & $6(5.6)$ \\
\hline Kenya, febrile children $<18$ y of age & 107 & $22(20.6)$ & $3(2.8)$ & $4(3.7)$ & 20 (18.7) & 0 & $2(1.9)$ \\
\hline Kenya, febrile adults & 119 & $86(72.3)$ & $31(26.1)$ & $43(36.1) \#$ & $56(47.1)$ & 0 & $5(4.2) \#$ \\
\hline
\end{tabular}

*Values are no. (\%) unless otherwise noted..

tIncludes persons that were IgG+ against $\geq 1$ bufavirus genotypes.

łUnclear bufavirus 2 and cutavirus blocking results were observed for $1 \S(0.3 \%), 2 \uparrow(2.0 \%)$, and $3 \#(2.5 \%)$ persons. These values are not included in overall seroprevalence calculations. 
of $<40$ years of age and $\geq 40$ years of age, we found that for younger adults in Iran, bufavirus seroprevalence was lower than that for older adults $(21 / 54$ [38.9\%] vs. 39/53 [73.6\%]; $\mathrm{p}=0.0003)$. However, a similar distinction was not observed for adults from Iraq or Kenya (Table 3). For veterinarians from Finland and adults from the United States, we found that younger adults also had a lower bufavirus seroprevalence, albeit without statistical power, because of the low overall prevalence of bufavirus IgG in these countries. When we divided the cohorts into persons $<30$ years of age and $\geq 30$ years of age, a similar trend was also observed for adults in Kenya (14/35 [56.0\%] vs. $70 / 92$ [76.1\%]; $p=0.0595$ ). This trend was not observed for persons in Iraq.

\section{Bufavirus IgG in Children in Kenya}

In Kenya, the bufavirus IgG prevalence in children was significantly lower than that in adults $(20.6 \%$ in children $<18$ years of age vs. $72.3 \%$ in adults; $p<0.0001$ ), but we observed similar proportions of bufavirus and a predominance of bufavirus 3 in both adults and children. (Table 2 ). When we divided the cohort of children into those $<5$ years of age and those 5-17 years of age, the prevalence of bufavirus IgG by age increased from $12 \%$ to $28.1 \%$ (Figure 2).

\section{Cutavirus and Tusavirus IgG in Adults and Children}

The prevalence of cutavirus IgG was generally low for all groups, ranging from $1.0 \%$ in Iraq to $5.6 \%$ in Iran, and cutavirus IgG was not detected in adults in the United States (Table 2). In veterinarians in Finland, cutavirus IgG (4.9\%) was more common than bufavirus $\operatorname{IgG}(1.9 \%)(\mathrm{p}=0.032)$. Two adults from Kenya and 1 veterinarian from Finland had both cutavirus IgG and bufavirus 2 IgG in their samples, which showed that these 2 antigenically similar viruses can infect the same person and elicit specific immune responses against each virus. However, for 6 patients $(1$ in Finland, 2 in Iraq, and 3 in Kenya), we could not determine whether the reactivity detected was specific for bufavirus 2 , cutavirus, or both. These results were not included in the final prevalence calculations (Table 2). Tusavirus IgG was not detected in any cohort (Table 2).

\section{Discussion}

During the current decade, several new parvoviruses have been detected, mostly because of the development of NGS methods. Bufavirus, tusavirus, and cutavirus are the newest of these viruses detected in human samples (2-4). Bufavirus has been associated with gastroenteritis, and cutavirus is being studied for its relationship to skin cancers $(4,8-10,12,24)$. However, studies that attempted to detect Bufavirus, tusavirus, and cutavirus DNA in any sample type or virus antibodies in serum samples have been infrequent (13).

We found high $(50 \%-85 \%)$ seroprevalences of bufavirus IgG in cohorts from the Middle East and Africa, which indicated that bufavirus infections are endemic to these areas. The observed low $(1.9 \%)$ seroprevalence in veterinarians in Finland is consistent with our previous results for staff members and medical students born in Finland (3.1\%) (12). The seroprevalence of bufavirus in the United States was similar to that in Finland, although the major genotype was different. In contrast to the diverse epidemiology of antibodies against bufavirus, antibodies against cutavirus appeared globally and were much more evenly distributed and showed a low prevalence. These results provide new insights on the global distribution and identify areas to which protoparvoviruses are endemic.

Because the difference in seroprevalence between persons born in Finland and staff born in Asia in our previous study could also be caused by more frequent animal contacts for 5 persons from Asia (12), we included veterinarians in this current study. However, no specific animal contacts for veterinarians from Finland were associated with bufavirus IgG or cutavirus IgG seropositivity. Although species jumps have occurred within protoparvoviruses (28), this result is consistent with the general rule of host-order specificity of parvoviruses (1). No animal contact information was available for persons from the Middle East, Kenya, or the United States.

\begin{tabular}{|c|c|c|c|c|c|}
\hline Cohort & Age group, $y$ & No. persons & No. $(\%)$ bufavirus IgG+ $(95 \% \mathrm{Cl})$ & $p$ value & Mean age, y (range) \\
\hline \multirow[t]{2}{*}{ Finland } & $<40$ & 165 & $1(0.6)(0.0-3.7)$ & 0.096 & $31.6(19-39)$ \\
\hline & $\geq 40$ & 149 & $5(3.4)(1.2-7.8)$ & & $49.7(40-79)$ \\
\hline \multirow[t]{2}{*}{ United States } & $<40$ & 38 & $1(2.6)(0.0-14.7)$ & 0.731 & $26.4(18-39)$ \\
\hline & $\geq 40$ & 46 & $2(4.3)(0.4-15.3)$ & & $53.5(40-72)$ \\
\hline \multirow[t]{2}{*}{ Iraq } & $\overline{<40}$ & 45 & $40(88.9)(76.1-95.6)$ & 0.325 & $30.8(18-39)$ \\
\hline & $\geq 40$ & 54 & $44(81.5)(69.0-89.8)$ & & $47.2(40-60)$ \\
\hline \multirow[t]{2}{*}{ Iran } & $<40$ & 54 & $21(38.9)(27.0-52.2)$ & 0.0003 & $30.1(18-39)$ \\
\hline & $\geq 40$ & 53 & 39 (73.6) (60.3-83.7) & & $55.0(40-77)$ \\
\hline \multirow[t]{2}{*}{ Kenya } & $<40$ & 52 & $37(71.2)(57.7-81.8)$ & 0.890 & $29.5(18-39)$ \\
\hline & $\geq 40$ & 65 & 47 (72.3) (60.4-81.8) & & $54.3(40-88)$ \\
\hline
\end{tabular}

*The exact age of 2 adults from Kenya and 10 veterinarians from Finland were not known and they were excluded from the analysis. However, the 2 were defined as adults on the basis of work-related sample collection site. + , positive. 
The age group results from Kenya, which showed continuously increasing seroprevalences of all 3 bufavirus genotypes, also showed that bufaviruses infect persons of all ages. The lower seroprevalence in children $<5$ years of age than in older children and adults indicates that the age of acquisition of bufavirus greatly differs from that of human bocavirus 1 (27) but resembles that for human parvovirus B19. Also for persons 5-17 years of age, an age-dependent increase was evident, but statistical power was insufficient to further divide these children into narrower age groups. In adults, the age-dependent increase in seroprevalence was detectable in Iran, but not in Kenya or Iraq. This difference could be caused by decreased bufavirus circulation in Iran during the past $30-40$ years or to socioeconomic or cultural changes over time. In Finland and the United States, age group prevalences were similar, albeit at low levels.

HIV-positive adults in Kenya did not have a higher seroprevalence of bufavirus IgG than HIV-negative adults. Bufavirus infection route(s) could therefore be hypothesized to differ from those for HIV infection.

The predominant bufavirus genotype (1 or 3 ) varied between countries studied. Bufavirus 2 was the second most common genotype in the 3 high-prevalence countries (Iraq, Iran, and Kenya). In sharp contrast, bufavirus 2 DNA has hitherto been found in the fecal sample of only 1 child in Burkina Faso, whereas all other bufavirus DNA-positive samples had genotypes 1 or $3(2,5,6,8$ 11,14 ). Our serologic data indicate that bufavirus 2 infections exist and are common in certain areas. Further studies of patients with primary infection should elucidate whether sample type(s) most suitable for detection of bufavirus 2, and also for genotypes 1 and 3, is stool or another type of sample.

In humans, IgG is induced against all 3 bufavirus genotypes and cutavirus, and immune reactions appear to be strong. In our previous report on bufavirus $\mathrm{IgG}$, the 3 bufavirus genotypes were shown to have no mutual crossreactivity (12). In this study, some cross-reactivity was observed between the 3 bufavirus genotypes, particularly among high OD samples in high-seroprevalence cohorts. In addition, cutavirus and bufavirus 2 cross-reactivity was common, which is consistent with the fact that amino acid identities are high within the VP2 gene ( $82 \%$ identity for the amino acid sequence). However, both genotype and species cross-reactivities could be distinguished from specific reactivity in the competition assay, similarly to what is shown for the 4 human bocaviruses (28).

Despite some VLP cross-reactivity in the EIA, the 3 bufavirus genotypes do not appear to be cross-protective. Several persons had antibodies against 2 or even 3 protoparvoviruses. Whether the previously formed antibodies against the first virus protects the human host against possible symptoms of the second related virus

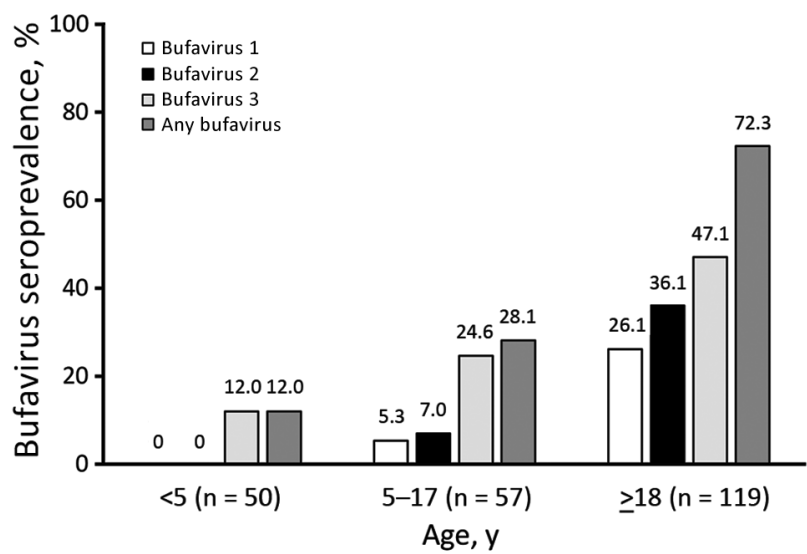

Figure 2. Seroprevalence of bufavirus in Kenya, by age. Several persons (mostly adults) had IgG against $\geq 1$ bufavirus genotypes; such persons are counted as 1 person in the bufavirus column. Differences in overall bufavirus seroprevalences were statistically significant between younger children vs. older children $(p=$ $0.04345)$, younger children vs. adults $(p<0.000001)$, and older children vs. adults $(p<0.000001)$.

infection, or worsen the symptoms through antibodydependent enhancement, is not known. However, it appears that immunity toward different protoparvoviruses does not hamper a sequential infection by heterologous virus (bufavirus genotype or cutavirus) or formation of specific antibodies toward this virus, which is in contrast to the phenomenon of original antigenic sin seen among human bocaviruses $(27,29)$. Longitudinal studies are needed to assess antibody and protection patterns, both during acute primary infections and during subsequent infections by the other human protoparvoviruses. It will be useful to determine the clinical pictures in these contexts, whether these viruses cause similar primary symptoms and illnesses, and whether they have the same or different tissue tropisms.

We did not detect tusavirus IgG in any cohort. This finding is consistent with results of 2 previous human studies, which reported no or infrequent evidence of tusavirus $(3,12)$. In addition, a study has reported sequences with some resemblance to tusavirus: a metagenomic analysis of fur seals in Brazil described partial sequences with $39 \%-82 \%$ amino acid similarity to tusavirus (23). Further studies on tusavirus DNA or antibodies are needed to determine whether tusavirus is a human or an animal parvovirus whose original detection in human feces was caused by consumption of meat or other products of a tusavirusinfected animal.

In conclusion, we observed major differences in seroprevalence of bufavirus when we compared Finland and the United States with the Middle East and Kenya. The high seroprevalence of bufavirus in the Middle East and Africa provides new opportunities for detecting bufavirus primary 
infections because these infections seem to be endemic to these regions. The predominant bufavirus genotype varied: bufavirus 1 was the most prevalent type in Finland and in the Middle East, and bufavirus 3 was the most prevalent type in the United States and in Kenya. Although IgG cross-reactivity was commonly observed, virus-specific antibodies could be distinguished from cross-reactivity by the competition assay. In contrast to bufavirus infections, cutavirus infections were distributed evenly and at found at low prevalences in all countries studied; for blood donors in the United States no virus IgG was detected. Tusavirus IgG was not detected in any cohorts studied.

This study was supported by the Academy of Finland (grants \#1257964 and \#277590), the Jane and Aatos Erkko Foundation, the Sigrid Jusélius Foundation, the Medical Society of Finland, the Research Funds of the University of Helsinki, the Helsinki University Hospital Research and Education Fund, the Life and Health Medical Grant Association, and the Finnish Work Environment Fund. E.V. was supported by the Clinical Chemistry Foundation, the Biomedicum Helsinki Foundation, the Finnish Society for Study of Infectious Diseases, the Otto A. Malm Foundation, and the Jenny and Antti Wihuri Foundation; P.M.K. was supported by the Orion-Farmos Research Foundation; and M.M. was supported by the Center for International Mobility, Finland.

\section{About the Author}

Ms. Väisänen is a doctoral candidate in the Department of Virology, University of Helsinki, Helsinki, Finland. Her research interests are clinical aspects and molecular biology of the newly discovered parvoviruses.

\section{References}

1. Cotmore SF, Agbandje-McKenna M, Chiorini JA, Mukha DV, Pintel DJ, Qiu J, et al. The family Parvoviridae. Arch Virol. 2014;159:1239-47. http://dx.doi.org/10.1007/s00705-013-1914-1

2. Phan TG, Vo NP, Bonkoungou IJ, Kapoor A, Barro N, O’Ryan M, et al. Acute diarrhea in West African children: diverse enteric viruses and a novel parvovirus genus. J Virol. 2012;86:11024-30. http://dx.doi.org/10.1128/JVI.01427-12

3. Phan TG, Sdiri-Loulizi K, Aouni M, Ambert-Balay K, Pothier P, Deng X, et al. New parvovirus in child with unexplained diarrhea, Tunisia. Emerg Infect Dis. 2014;20:1911-3. http://dx.doi.org/10.3201/eid2011.140428

4. Phan TG, Dreno B, da Costa AC, Li L, Orlandi P, Deng X, et al. A new protoparvovirus in human fecal samples and cutaneous $\mathrm{T}$ cell lymphomas (mycosis fungoides). Virology. 2016;496:299-305. http://dx.doi.org/10.1016/j.virol.2016.06.013

5. Yahiro T, Wangchuk S, Tshering K, Bandhari P, Zangmo S, Dorji $\mathrm{T}$, et al. Novel human bufavirus genotype 3 in children with severe diarrhea, Bhutan. Emerg Infect Dis. 2014;20:1037-9. http://dx.doi.org/10.3201/eid2006.131430

6. Väisänen E, Kuisma I, Phan TG, Delwart E, Lappalainen M, Tarkka E, et al. Bufavirus in feces of patients with gastroenteritis, Finland. Emerg Infect Dis. 2014;20:1077-9. http://dx.doi.org/10.3201/eid2006.131674
7. Smits SL, Schapendonk CM, van Beek J, Vennema H, Schürch AC, Schipper D, et al. New viruses in idiopathic human diarrhea cases, the Netherlands. Emerg Infect Dis. 2014;20:1218-22. http://dx.doi.org/10.3201/eid2007.140190

8. Chieochansin T, Vutithanachot V, Theamboonlers A, Poovorawan Y. Bufavirus in fecal specimens of patients with and without diarrhea in Thailand. Arch Virol. 2015;160:1781-4. http://dx.doi.org/10.1007/s00705-015-2441-z

9. Altay A, Yahiro T, Bozdayi G, Matsumoto T, Sahin F, Ozkan S, et al. Bufavirus genotype 3 in Turkish children with severe diarrhoea. Clin Microbiol Infect. 2015;21:965.e1-4. http://dx.doi.org/10.1016/j.cmi.2015.06.006

10. Huang DD, Wang W, Lu QB, Zhao J, Guo CT, Wang HY, et al. Identification of bufavirus- 1 and bufavirus- 3 in feces of patients with acute diarrhea, China. Sci Rep. 2015;5:13272. http://dx.doi.org/10.1038/srep13272

11. Ayouni S, Estienney M, Hammami S, Neji Guediche M, Pothier P, Aouni M, et al. Cosavirus, salivirus and bufavirus in diarrheal Tunisian infants. PLoS One. 2016;11:e0162255. http://dx.doi.org/10.1371/journal.pone.0162255

12. Väisänen E, Paloniemi M, Kuisma I, Lithovius V, Kumar A, Franssila R, et al. Epidemiology of two human protoparvoviruses, bufavirus and tusavirus. Sci Rep. 2016;6:39267. http://dx.doi.org/10.1038/srep39267

13. Väisänen E, Fu Y, Hedman K, Söderlund-Venermo M. Human protoparvoviruses. Viruses. 2017;9:E354. http://dx.doi.org/ $10.3390 / \mathrm{v} 9110354$

14. Altan E, Del Valle Mendoza J, Deng X, Phan TG, Sadeghi M, Delwart EL. Small circular rep-encoding single-stranded DNA genomes in Peruvian diarrhea virome. Genome Announc. 2017;5:e00822-17. http://dx.doi.org/10.1128/genomeA.00822-17

15. Qiu J, Söderlund-Venermo M, Young NS. Human parvoviruses. Clin Microbiol Rev. 2017;30:43-113. http://dx.doi.org/10.1128/ CMR.00040-16

16. Handley SA, Thackray LB, Zhao G, Presti R, Miller AD, Droit L, et al. Pathogenic simian immunodeficiency virus infection is associated with expansion of the enteric virome. Cell. 2012;151:253-66. http://dx.doi.org/10.1016/j.cell.2012.09.024

17. Sasaki M, Orba Y, Anindita PD, Ishii A, Ueno K, Hang'ombe BM, et al. Distinct lineages of bufavirus in wild shrews and nonhuman primates. Emerg Infect Dis. 2015;21:1230-3. http://dx.doi.org/10.3201/eid2107.141969

18. Kemenesi G, Dallos B, Görföl T, Estók P, Boldogh S, Kurucz K, et al. Genetic diversity and recombination within bufaviruses: detection of a novel strain in Hungarian bats. Infect Genet Evol. 2015;33:288-92. http://dx.doi.org/10.1016/j.meegid.2015.05.017

19. Sasaki M, Gonzalez G, Wada Y, Setiyono A, Handharyani E, Rahmadani I, et al. Divergent bufavirus harboured in megabats represents a new lineage of parvoviruses. Sci Rep. 2016;6:24257. http://dx.doi.org/10.1038/srep24257

20. Yang S, Liu D, Wang Y, Qu F, He Y, Sun Z, et al. Bufavirus protoparvovirus in feces of wild rats in China. Virus Genes. 2016;52:130-3. http://dx.doi.org/10.1007/s11262-015-1262-1

21. Hargitai R, Pankovics P, Kertész AM, Bíró H, Boros Á, Phan TG, et al. Detection and genetic characterization of a novel parvovirus distantly related to human bufavirus in domestic pigs. Arch Virol. 2016;161:1033-7. http://dx.doi.org/10.1007/ s00705-015-2732-4

22. Liu L, Schwarz L, Ullman K, Ahola H, Qiu Y, Ma Z, et al. Identification of a novel bufavirus in domestic pigs by a viral metagenomic approach. J Gen Virol. 2016;97:1592-6. http://dx.doi.org/10.1099/jgv.0.000476

23. Kluge M, Campos FS, Tavares M, de Amorim DB, Valdez FP, Giongo A, et al. Metagenomic survey of viral diversity obtained from feces of Subantarctic and South American fur seals. PLoS One. 2016;11:e0151921. http://dx.doi.org/10.1371/journal.pone.0151921 
24. Mollerup S, Fridholm H, Vinner L, Kjartansdóttir KR, Friis-Nielsen J, Asplund M, et al. Cutavirus in cutaneous malignant melanoma. Emerg Infect Dis. 2017;23:363-5. http://dx.doi.org/10.3201/eid2302.161564

25. Kantala T, Kinnunen PM, Oristo S, Jokelainen P, Vapalahti O, Maunula L. Hepatitis E virus antibodies in Finnish veterinarians. Zoonoses Public Health. 2017;64:232-8. http://dx.doi.org/10.1111/ zph.12312

26. Barakat AM, Smura T, Kuivanen S, Huhtamo E, Kurkela S, Putkuri N, et al. The presence and seroprevalence of arthropod-borne viruses in Nasiriyah governorate, southern Iraq: a cross-sectional study. Am J Trop Med Hyg. 2016;94:794-9. http://dx.doi.org/10.4269/ajtmh.15-0622

27. Kantola K, Hedman L, Tanner L, Simell V, Mäkinen M, Partanen $\mathrm{J}$, et al. B-cell responses to human bocaviruses 1-4: new insights from a childhood follow-up study. PLoS One. 2015;10:e0139096. http://dx.doi.org/10.1371/journal.pone.0139096

28. Hoelzer K, Parrish CR. The emergence of parvoviruses of carnivores. Vet Res. 2010;41:39. http://dx.doi.org/10.1051/ vetres/2010011

29. Li X, Kantola K, Hedman L, Arku B, Hedman K, Söderlund-Venermo M. Original antigenic sin with human bocaviruses 1-4. J Gen Virol. 2015;96:3099-108. http://dx.doi.org/10.1099/jgv.0.000253

Address for correspondence: Maria Söderlund-Venermo, Faculty of Medicine, Department of Virology, University of Helsinki, Haartmaninkatu 3, 00290 Helsinki, Finland; email:

maria.soderlund-venermo@helsinki.fi

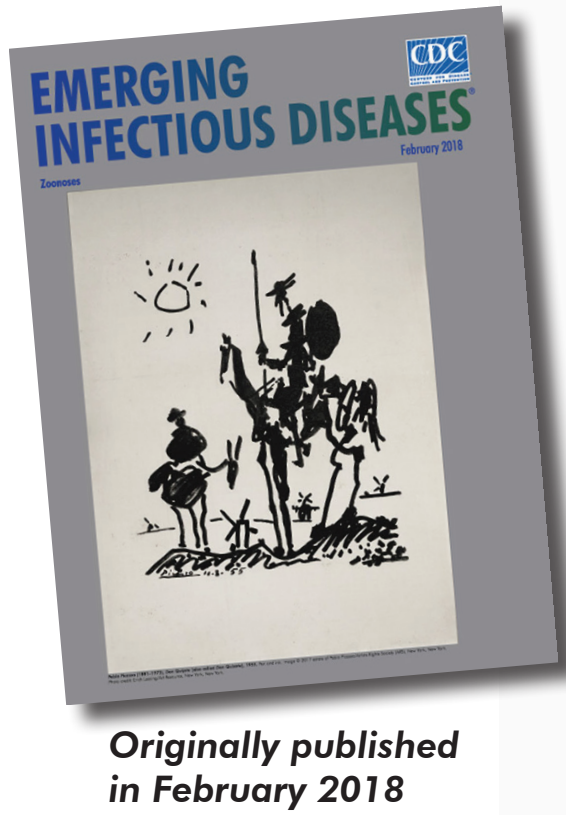

\section{etymologia revisited}

\section{Parvovirus [pahr' vo-vi"res]}

$\mathrm{V}$ iruses of the family Parvoviridae (Latin parvum [meaning small or tiny]) are among the smallest viruses described, $18-28 \mathrm{~nm}$ in diameter. There are 2 subfamilies of the family Parvoviridae: Parvovirinae and Densovirinae (Latin denso [thick or compact]). Parvovirinae may infect humans, but Densovirinae infect only arthropods. Structurally, these viruses are nonenveloped, icosahedral viruses that contain a single-stranded linear DNA genome.

The small size of these viruses might account for their late discovery. In 1974, the first pathogenic human parvovirus was discovered and named B19 from the coding of a serum sample, number 19 in panel $\mathrm{B}$, that gave anomalous results during testing for hepatitis B. Although human B19 infections are more often asymptomatic or lead to mild rash illnesses and arthralgias, they can also cause severe anemia in fetuses and in persons with underlying hemoglobinopathies.

\section{Sources}

1. Cossart YE, Field AM, Cant B, Widdows D. Parvovirus-like particles in human sera. Lancet. 1975;1:72-3. http://dx.doi.org/10.1016/S0140-6736(75)91074-0

2. Pattison JR. B19 virus - a pathogenic human parvovirus. Blood Rev. 1987;1:58-64. http://dx.doi.org/10.1016/0268-960X (87)90020-8

3. Servey JT, Reamy BV, Hodge J. Clinical presentations of parvovirus B19 infection. Am Fam Physician. 2007;75:373-6.

4. Tattersall P, Cotmore SF. Parvoviruses. In: Topley WW, Wilson GS, editors. Topley \& Wilson's microbiology and microbial infections. Vol. 1, 10th ed. London: Hodder Arnold; 2005. p. 407-39.

5. Young NS, Brown KE. Parvovirus B19. N Engl J Med. 2004;350:586-97. http://dx.doi.org/10.1056/NEJMra030840 